the addition of $\mathrm{Mn}^{2+}$ ions ( $\mathrm{mm}$ ) or by an increased concentration of $\mathrm{Mg}^{2+}$ ions (5 mM). The sterolsynthesizing system has an absolute requirement for $\mathrm{Mg}^{2+}$ or $\mathrm{Mn}^{2+}$ ions.

5. Enzyme systems containing old preparations of microsomes have also a requirement for adenosine triphosphate higher than those containing fresh microsomes. Sodium fluoride, which has no effect on fresh preparations, enhances the stimulating effects of high concentrations of adenosine triphosphate on old preparations of microsomes.

6. During ageing, substances inhibiting sterol synthesis appear in the microsomal preparations.

7. Microsome preparations as old as four months can be fully reactivated by a suitable combination of $\mathrm{Mg}^{2+}$ ions, adenosine triphosphate and sodium fluoride.

We wish to thank Mr Terry Flynn for his skilful technical assistance.

\section{REFERENCES}

Bucher, N. L. R. \& McGarrahan, K. (1956). J. biol. Chem. 222, 1.

Cornforth, J. W., Cornforth, R. H., Pelter, A., Horning, M. \& Popják, G. (1959). Tetrahedron, 5, 311.

Cornforth, J. W., Cornforth, R. H., Popják, G. \& Gore, I. Y. (1958). Biochem. J. 69, 146.

Gosselin, L. \& Popják, G. (1958). Biochem. J. 70, 19 P.

Popják, G., Gosselin, L., Gore, I. Y. \& Gould, R. G. (1958). Biochem. J. 69, 238.

\title{
The Metabolism of $\left[16-{ }^{-14} \mathrm{C}\right]$ Oestrone in vitro
}

\author{
By P. H. JELLINCK* \\ Department of Biochemistry, McGill University, Montreal, Canada and \\ the Medical College of St Bartholomew's Hospital, London, E.C. 1
}

(Received 25 September 1958)

Since the original demonstration by Zondek (1934) that liver mince rapidly inactivates oestrogens, many workers have studied the metabolism of oestrone and oestradiol in vitro, employing loss of biological activity to follow hormone-degradation (Heller, 1940; Engel \& Rosenberg, 1945; Levy, 1947; De Meio, Rakoff, Cantarow \& Paschkis, 1948; Pearlman \& De Meio, 1949). Ryan \& Engel (1953), by means of countercurrent distribution and fluorometric analysis, found that after incubation of these two natural oestrogens with rat-liver slices over $50 \%$ of the starting material was converted into unknown metabolites. More recent experiments with $\left[{ }^{14} \mathrm{C}\right]$ oestrogens in vivo have supported these findings. Thus Valcourt, Thayer, Doisy, Elliott \& Doisy (1955), on administering [16-14 C]oestrone to rats, found that even after enzymic hydrolysis of conjugates only one-third of the ${ }^{14} \mathrm{C}$ excreted in bile and urine was extractable with ether, a solvent in which steroid oestrogens are readily soluble. Similarly, Beer \& Gallagher (1955) showed that extraction with ether failed to remove all the radioactivity from hydrolysed urine of human patients injected with $\left[{ }^{14} \mathrm{C}\right]$ oestrone or $\left[{ }^{14} \mathrm{C}\right]$ oestradiol, and, in perfusion experiments with radioactive oestrone, Wotiz, Ziskind \& Ringler (1958) observed a large amount of chloroforminsoluble material containing ${ }^{14} \mathrm{C}$ in the hydrolysed dialysates of rat plasma.

* Present address: Courtauld Institute of Biochemistry, Middlesex Hospital Medical School, London, W. 1.
Very little is known about the nature of the inactivation products of oestrogens, but there is evidence that oestrone and oestradiol are attacked by an oxidative enzyme system. Thus Heller (1940) found that cyanide inhibited the inactivation of oestrogens by liver, suggesting that an oxidase was involved, and in support of this theory Westerfeld (1940) and Graubard \& Pincus (1941) showed that oxidases from plant sources were capable of acting on oestrogens. Levy (1947), using rat-liver homogenates, also showed inhibition by cyanide as well as by azide and carbon monoxide, and suggested that the cytochrome system was involved. He found that inactivation of oestradiol was greatly reduced under anaerobic conditions, and this was confirmed by De Meio et al. (1948), who, however, found very little inhibition of oestrogen-inactivation by cyanide or azide and none by malonate, iodoacetate or fluoride. In all these experiments very little conjugation was observed and the results which were obtained by bioassay methods give no indication about the extent to which the original steroid molecule had been altered.

The advent of isotope-labelled oestrogens, however, made the solution of this problem more feasible, and the present investigation was therefore undertaken to determine whether the watersoluble ether-insoluble metabolites observed in vivo are also formed in vitro and, if so, to try and discover the nature of these products and the effect of enzyme inhibitors on their formation. 


\section{EXPERIMENTAL}

Materials. [16- $\left.{ }^{14} \mathrm{C}\right]$ Oestrone prepared by Thompson (1951) was shown to be radiochemically pure by chromatography with the toluene-propylene glycol system (Jellinck, 1953) followed by radioautography of the developed chromatogram. For this purpose, enough radioactive material was used to enable $0.1 \%$ of impurity to be detected.

Ether was shaken with an acidified solution of $\mathrm{FeSO}_{4}$ to remove peroxides, and distilled; ethanol was distilled over $\mathrm{CaO}$. Toluene (thiophen-free) and methylene chloride used for chromatography were both distilled.

Buffer solutions. Phosphate-saline (Krebs \& Eggleston, 1940), $\mathrm{pH} \mathrm{7.4,} \mathrm{was} \mathrm{used} \mathrm{for} \mathrm{the} \mathrm{liver,} \mathrm{and} \mathrm{Krebs-Ringer}$ bicarbonate solution (Cohen, 1949) for the placental incubations. The medium was 25 mM-sodium phosphate buffer, pH 6.1, for the mushroom tyrosinase experiment and no buffer was added to the blood. The $\mathrm{pH}$ of all buffer solutions was measured with a standardized glass electrode before use and the $\mathrm{pH}$ of each mixture was checked with indicator at the end of the experiment.

Tissues. Rat liver was obtained from young adult male animals killed by a blow on the back of the neck, and the slices were prepared with a Stadie-Riggs tissue slicer. To prepare the homogenate, rat liver in phosphate saline was disintegrated for $5 \mathrm{~min}$. in a tissue blender (MSE Ato-Mix). A small piece of human liver with no visible signs of abnormality was obtained after laparotomy from a 56. year-old female patient.

The human placentae (full-term) were placed immediately after delivery into ice-cold $\mathrm{NaCl}$ solution $(0 \cdot 154 \mathrm{M})$ and small pieces were removed with scissors from both the maternal and foetal sides. They were then ground with coarse sand in a mortar under Krebs-Ringer bicarbonate solution.

Human whole blood which had been stored for $24 \mathrm{hr}$. at $4^{\circ}$ with added sodium citrate (25 mM) and glucose $(0.4 \%)$ was used.

Mushroom tyrosinase. Fresh mushrooms (5 g.) were ground with sand under water $(25 \mathrm{ml}$.) and centrifuged after straining through muslin. The activity of the preparation was tested with catechol as substrate by the method of Wills \& Wormall (1950). This crude extract would, of course, contain several phenol oxidases.

Assay of radioactivity. This was carried out with a windowless gas-flow counter (Nuclear Instruments, Chicago, Ill., U.S.A.) operating at $40-50 \%$ efficiency or with a thin mica-window Geiger-Müller tube (Ecko type EHM 2S) coupled to a scaler and E.H.T. unit (Panax type $D$ 554). The samples for plating, with the exception of the aqueous ones, were dissolved in ethanol and evaporated at 60-70 under an infrared lamp. Copper disks (diameter $2.5 \mathrm{~cm}$.) were used for the windowless counter and stainlesssteel cupped planchets (internal diameter $1.5 \mathrm{~cm}$.) for the end-window instrument and for the $\mathrm{BaCO}_{3}$ assay. Whenever possible, samples were plated at infinite thinness ( $100 \mu \mathrm{g}$. or less of solids) or the count was corrected for selfabsorption after the addition of a steroid standard of very high specific activity and negligible weight (Heard et al. 1954). Carbon dioxide collected during the incubation of rat liver was precipitated as $\mathrm{BaCO}_{3}$ by a procedure described by Calvin (1949). Half the total quantity of solid was transferred as a slurry in ethanol to a stainless-steel cupped planchet, dried in an oven at $110-120^{\circ}$ and assayed with the windowless counter. Tissues were dried, pulverized in a mortar and counted in the same way as the $\mathrm{BaCO}_{3}$. Samples were plated in duplicate and counting was continued long enough to give a statistical accuracy of $5 \%$ or better. A standard count with $\left[4^{-14} \mathrm{C}\right]$ testosterone was taken daily and the counts given by the samples were corrected for background.

Chromatography. The methods were as described by Burton, Zaffaroni \& Keutmann (1951) and Axelrod (1953), except for slight modifications. Strips of Whatman no. 1 filter paper $(1 \mathrm{~cm} . \times 34 \mathrm{~cm}$.), which had been washed successively with acetic acid $(2 \mathrm{~N})$, water, methanol and toluene, were dipped into the stationary phase (formamidemethanol, 1:1, or propylene glycol) and well blotted between filter papers. The mixtures under investigation were dissolved in ethanol $(0 \cdot 1-0.2 \mathrm{ml}$.) for application to the paper and the spots dried in a stream of $\mathrm{N}_{2}$ to prevent the formation of any steroid-oxidation products. The chromatograms were developed by downward flow of toluene or methylene chloride which had been equilibrated with the stationary phase. The tanks were maintained at a constant temperature of $25^{\circ}$. In both systems used the solvent was allowed to run off the end of the paper strip so that the rates of movement of metabolites are not expressed as $R_{F}$ but relative to that of a faster-moving reference compound.

Radioautography. The dried chromatograms were stapled on to X-ray film (Kodak No Screen) and kept in close contact inside cassettes for a period depending on the radioactivity of the material. For ${ }^{14} \mathrm{C}, 24 \mathrm{hr}$. was found adequate for activities greater than $0.005 \mu \mathrm{c} / \mathrm{cm}^{2}\left(10^{4}\right.$ disintegrations/min./cm. ${ }^{2}$ approx.).

Incubations. The liver slices $(0 \cdot 8-1 \cdot 0 \mathrm{~g}$. wet wt.) and medium $\left(25 \mathrm{ml}\right.$.) which had been saturated with $\mathrm{O}_{2}$ were shaken for $3 \mathrm{hr}$. at $38^{\circ}$ in conical flasks (100 ml.) with tightfitting rubber stoppers. The radioactive oestrone was added dissolved in ethanol $\left(0.1 \mathrm{ml}\right.$.) and the $\mathrm{CO}_{2}$ evolved during the incubation was absorbed in $30 \% \mathrm{KOH}(2 \mathrm{ml}$.) contained in small test tubes hanging vertically from the stoppers. The liver homogenate $(0 \cdot 8-1 \cdot 0 \mathrm{~g}$. wet wt.) in phosphate-saline $(25 \mathrm{ml}$.) was treated in a similar way but no $\mathrm{CO}_{2}$ was collected.

The ground placental tissue (8-9 g. wet wt.) in KrebsRinger bicarbonate solution $(60 \mathrm{ml}$.) was shaken for $3 \mathrm{hr}$. at $38^{\circ}$ in conical flasks $\left(250 \mathrm{ml}\right.$.) with $\mathrm{CO}_{2}+\mathrm{O}_{2}(5: 95)$ bubbling through the liquid at a slow rate during the entire incubation period. Glucose $(0 \cdot 1 \mathrm{~g}$.) was also added to the medium and the cestrone was dissolved in $0.5 \mathrm{ml}$. of propylene glycol.

Blood $(30 \mathrm{ml}$.) was incubated with shaking in a conical flask ( $100 \mathrm{ml}$.) at $38^{\circ}$ for $2 \mathrm{hr}$., during which $\mathrm{O}_{2}$ was bubbled through continuously. The added oestrone was dissolved in $0.3 \mathrm{ml}$. of propylene glycol.

The buffered mushroom extract $(25 \mathrm{ml}$.) was incubated for $3 \mathrm{hr}$.

Extraction and fractionation. The procedure (Fig. 1) was identical for the liver slices and the placental brei. The medium was decanted immediately after incubation, filtered and the tissues were washed twice with 0.6 vol. of water. The liver homogenate was centrifuged before decantation. The medium and aqueous washings and also the mushroom tyrosinase solution were extracted three times with equal volumes of ether and the tissues were kept 
overnight under ethanol $(20 \mathrm{ml}$.), filtered and washed twice more with this volume of solvent. The ethereal fraction was dried over anhydrous $\mathrm{Na}_{2} \mathrm{SO}_{4}$, filtered and the solvent removed in vacuo at $25^{\circ}$. The residue from the ethereal fraction was dissolved in ethanol for assay of radioactivity and the ethanolic and aqueous fractions were plated with. out further treatment.

The blood was centrifuged and the cells were washed four times with an equal volume of $\mathrm{KCl}(0 \cdot 154 \mathrm{M})$. The plasma was acidified with $\mathrm{HCl}(0.01 \mathrm{~N}$ ) to $\mathrm{pH} 6.5$ (glass electrode) and extracted with three equal volumes of ether. The extract was dried, filtered, evaporated to dryness and dissolved in ethanol for assay of ${ }^{14} \mathrm{C}$. The erythrocytes were haemolysed by the addition of an equal volume of ethanolether $(3: 1, v / v)$, well stirred, centrifuged and washed three times with an equal volume of ethanol.

Examination of aqueous fractions. Portions $(5 \mathrm{ml}$.) of the aqueous solutions were acidified to $\mathrm{pH} \mathrm{1-2}$ with $12 \mathrm{~N}-\mathrm{HCl}$ and extracted with an equal volume of ether or butan-1-ol. The $\mathrm{pH}$ was adjusted to $12-13$ with $\mathrm{N}-\mathrm{NaOH}$ and hydrolysis

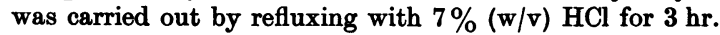
In all cases the amount of ${ }^{14} \mathrm{C}$ removed by ether or butanol from the aqueous fractions was determined from the difference between the activities of the aqueous fractions before and after extraction.

Examination of ethereal fractions. Portions of the dried ethereal fractions, usually containing over $0.005 \mu \mathrm{C}$ of ${ }^{14} \mathrm{C}$, were examined for oestrone and cestradiol with the toluenepropylene glycol system followed by radioautography. Compounds with $R_{F}$ values much smaller than that of oestradiol were eluted from the appropriate sections of the paper strip with methanol $(3 \times 5 \mathrm{ml}$.) and after concentration of the eluate by evaporation in a stream of $\mathrm{N}_{2}$ they were re-examined by chromatography on the methylene chloride-formamide system and radioautography. The eluted compounds were also analysed by the isotopedilution technique (Francis, Mulligan \& Wormall, 1954). The added oestriol (18 mg.) was crystallized from ethanol.

\section{RESULTS AND DISCUSSION}

The results in Table 1 show that liver and the phenol oxidases from mushrooms have a marked ability for converting oestrone into water-soluble ether-insoluble metabolites and that blood and placental breis are ineffective in this respect.

A considerable proportion of the ${ }^{14} \mathrm{C}$ cannot be removed from fresh or boiled liver slices by washing with water and this adsorption is also observed with placental tissue and to a smaller extent with blood.

The formation of water-soluble, ether-insoluble radioactive products by rat-liver slices is almost completely abolished by cyanide, but malonate had no inhibitory effect.

The persistence of a small but significant amount of radioactivity in the liver even after repeated extraction with ethanol may represent actual incorporation of ${ }^{14} \mathrm{C}$ into the tissue, but this will need further verification. In the presence of cyanide the rat-liver slices retained only negligible amounts of radioactivity, in spite of the fact that there was more adsorbed ${ }^{14} \mathrm{C}$ under these conditions, as shown by the activity of the ethanolic extracts. Once again malonate had no effect on this 'incorporation'.

The discrepancies in total recovery of radioactivity are most marked when small weights of $\left[{ }^{14} \mathrm{C}\right]$ oestrone are used and are due to losses in manipulation, probably by adsorption on to the glassware. Thus losses were observed even in the absence of tissue, and with boiled liver. The greatest discrepancies, however, occurred whenever water-soluble metabolites were formed, and since no radioactive carbon dioxide was evolved during the incubations, it may be that some of the oestrone-breakdown products are volatile and are lost when the samples are evaporated to dryness for counting. Another source of error arises in assaying the dry tissue powder for ${ }^{14} \mathrm{C}$, since the count rates cannot be corrected reliably for self-absorption. One more minor $(<5 \%)$ contributing factor is the counting error.

Another object of the experiment was to gain information about the nature of the ether-insoluble

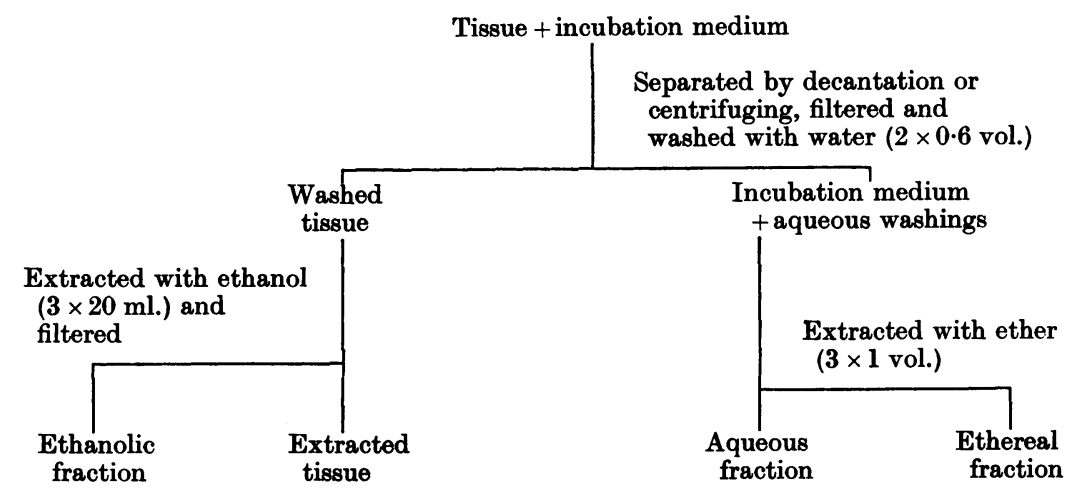

Fig. 1. Fractionation scheme: after incubation of $\left[16-{ }^{14} \mathrm{C}\right]$ oestrone with tissues. 


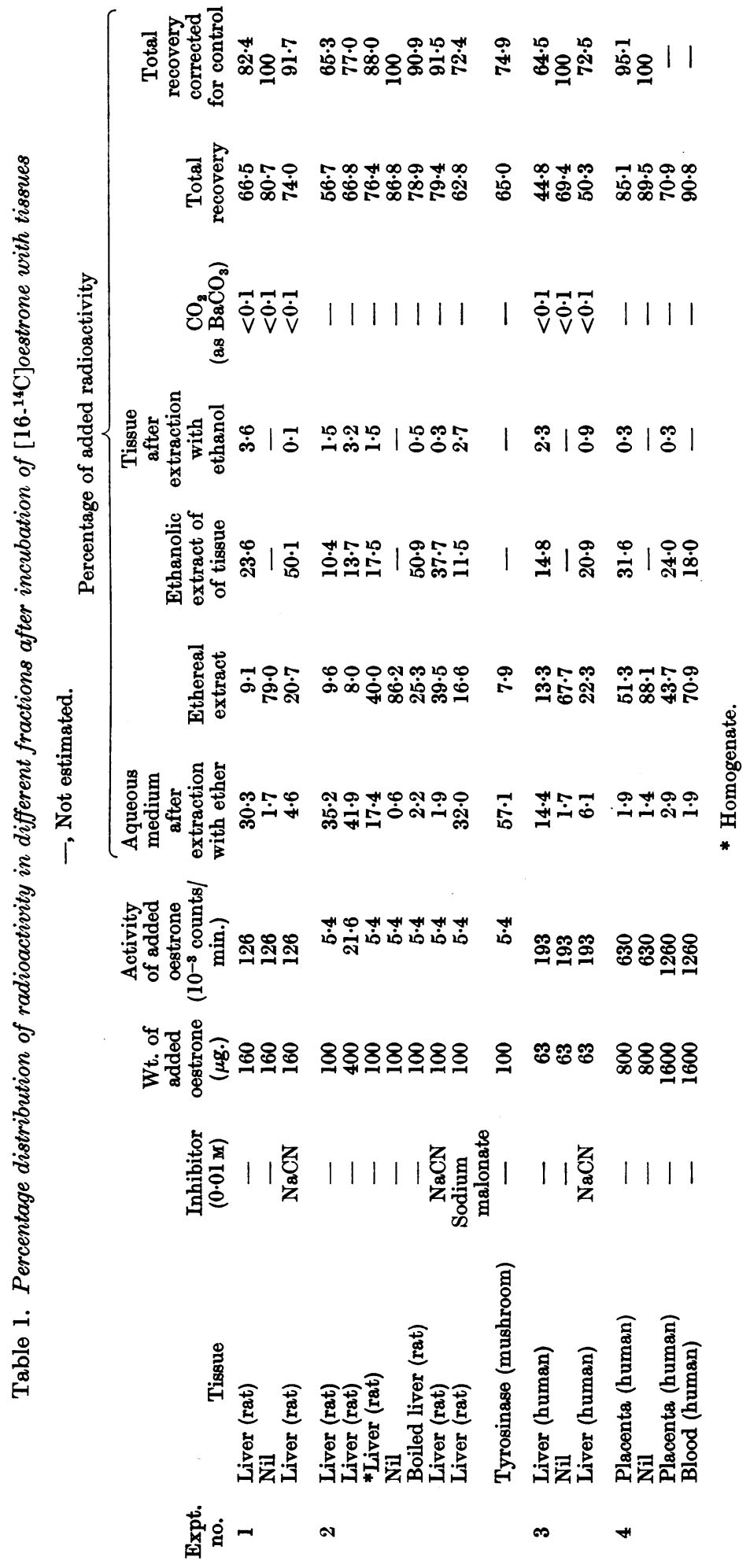


products formed in vitro from oestrone and to determine whether liver and mushroom tyrosinase gave rise to identical metabolites. Table 2 shows the behaviour of the ${ }^{14} \mathrm{C}$ compounds in the etherextracted aqueous fractions under different physical conditions. Lowering the $\mathrm{pH}$ results in a considerable amount of the radioactivity passing into the ether layer on extracting either the liver or the tyrosinase aqueous fractions, which might indicate the presence of one or more acidic metabolites. These would exist in the un-ionized form at pH 1-2 and should therefore be more ether-soluble under these conditions. Butanol and ethanol remove about $50 \%$ of the radioactivity at $\mathrm{pH} \mathbf{7 \cdot 4}$ from the aqueous fraction of the liver, but only a relatively small amount of ${ }^{14} \mathrm{C}$ passes into butanol from the corresponding tyrosinase fraction. The small quantity that is extracted can be accounted for by the partial solubility of water in this organic solvent.

Lowering the $\mathrm{pH}$ results in no further extraction of radioactivity by butanol from the tyrosinase solution, but with liver this solvent removes an amount $(84.0 \%)$ approximately equal to the sum of the amounts removed by ether from acid solution $(33.9 \%)$ and by butanol from neutral solution $(53.1 \%)$. This suggests the existence of another type of metabolite soluble at both acid and neutral $\mathrm{pH}$ which is formed by liver but not by the mushroom phenol oxidases.

A conjugate of oestrone or that of a closely related steroid metabolite must be ruled out unless it were able to resist hydrolysis by $7 \%(w / v) ~ H C l$, since under these conditions no further etherextractable radioactive material is formed. Beer \& Gallagher (1955) have, however, presented evidence that glucuronosides may not be completely hydrolysed by refluxing with acid.

In the ethereal fractions of incubated liver and placenta the presence of unchanged oestrone and three more polar metabolites were revealed by chromatography followed by radioautography. Only the placental extracts were further examined since they contained considerably more ${ }^{14} \mathrm{C}$ than the liver ethereal fractions. Mixed chromatography with $\left[16^{14} \mathrm{C}\right]$ oestradiol with the toluenepropylene glycol system showed the absence of this oestrogen and the presence of a metabolite more polar than oestradiol $\left(R_{\text {oestradiol }} \mathbf{0 . 6 6}\right)$, as well as another substance which had hardly moved from the starting line in $24 \mathrm{hr}$. Chromatography on the methylene chloride-formamide system (40 hr.) revealed that this latter compound was a mixture of two oestrone metabolites $\left(R_{\text {oestriol }} 0.91\right.$ and 0.33 , with the faster-moving one differing from oestriol as confirmed by isotope-dilution analysis. All these ether-soluble compounds were also formed in the presence of cyanide. No further investigation was carried out on the ethereal fractions owing to the large number of oestrone metabolites that can theoretically exist and the difficulties involved in preparing any such oestrone analogue.

Finally, a result which confirms the findings in vivo of Valcourt et al. (1955) is the absence of detectable radioactivity in the carbon dioxide collected during the incubation of liver slices, showing that C-16 at least of the steroid nucleus remains intact. The evidence therefore is against rupture of ring $\mathrm{D}$ and the mushroom tyrosinase results are in favour of an initial attack in ring $A$ of oestrone. The phenol oxidases are known to convert phenols into the corresponding $o$-quinones and there is no reason why a reaction of this type catalysed by similar oxidizing enzymes should not take place in liver tissue, with perhaps subsequent ring-opening and oxidation to a carboxylic acid. Some more circumstantial evidence in favour of

Table 2. Examination of the ether-extracted aqueous fractions after incubation of $\left[16-{ }^{14} \mathrm{C}\right]$ oestrone with liver and mushroom tyrosinase

$\begin{array}{lc}\text { Liver } \quad \text { Treatment } & \begin{array}{c}\text { Percentage of }{ }^{14} \mathrm{C} \\ \text { removed from } \\ \text { aqueous fraction }\end{array} \\ \text { Acidified and extracted with ether } & 33 \cdot 9 \\ \text { Acidified and extracted with ether* } & 30 \cdot 8 \\ \text { Hydrolysed and extracted with ether } & 33 \cdot 1 \\ \text { Made alkaline and extracted with ether } & 9 \cdot 2 \\ \text { Evaporated to dryness and extracted with ethanol } & 50 \cdot 0 \\ \text { Extracted with butanol } & 53 \cdot 1 \\ \text { Acidified and extracted with butanol } & 84 \cdot 0 \\ \text { Tyrosinase } & \\ \text { Acidified and extracted with ether } & 51 \cdot 4 \\ \text { Extracted with butanol } & 11 \cdot 6 \\ \text { Acidified and extracted with butanol } & 53 \cdot 4\end{array}$

* Aqueous fraction from the incubation of $100 \mu \mathrm{g}$. of oestrone. All other results for liver refer to the aqueous fraction of the incubation of $400 \mu \mathrm{g}$. of oestrone (see Table 1 ). 
attack at ring $A$ is provided by the recent isolation of 2-methoxyoestrone from human urine by Kraychy \& Gallagher (1957). It suggests the conversion of oestrone into a catechol which might then be protected from rapid degradation in the body by methylation. Garst \& Friedgood (1952) have obtained a similar type of compound from urine, for which they proposed an oestriol catechol or quinone structure. The formation of neutral metabolites from phenolic oestrogens in vivo (Valcourt et al. 1955; Beer \& Gallagher, 1955) once more points to metabolic changes in ring $A$, whereas no trace of a marrianolic acid type of compound (Fieser \& Fieser, 1949) formed by oxidative fission of ring $\mathrm{D}$ of oestrone has ever been detected in the living organism.

\section{SUMMARY}

1. Incubation of rat- and human-liver slices and mushroom tyrosinase with $\left[16-^{14} \mathrm{C}\right]$ oestrone results in the formation of water-soluble ether-insoluble metabolites, in high percentage yield, which do not appear on incubating oestrone with placental tissue or blood.

2. Cyanide, but not malonate, inhibits the formation of such oestrone metabolites by liver slices and also the adsorption or incorporation of ${ }^{14} \mathrm{C}$ by this tissue.

3. The nature of the oestrone-degradation products has been investigated and it has been shown that liver forms probably non-steroidal oestrogen metabolites which differ in part from those formed by mushroom tyrosinase.

4. No radioactive carbon dioxide was evolved during the incubation of $\left[{ }^{14} \mathrm{C}\right]$ oestrone with liver.

5. Both liver and placenta are able to convert oestrone into ether-soluble metabolites even in the presence of cyanide, and with placenta these were shown to differ from either $17 \beta$-oestradiol or oestriol.

6. The evidence in favour of oestrone-degradation by initial attack in ring $A$ is discussed.

This work was originally started at McGill University, Montreal, during the tenure of a Postdoctorate Fellowship and I should like to thank the National Research Council, Ottawa, for financial support and acknowledge with gratitude the advice and constant encouragement given to me by the late Professor R. D. H. Heard, F.R.S. (Canada). I am also grateful to him for a generous gift of radioactive oestrone and oestradiol, to Parke, Davis and Co. Ltd., Detroit, Mich., U.S.A., for oestriol and to the Royal
Victoria Hospital, Montreal, for making available the human tissues. The project was continued at the Medical College of St Bartholomew's Hospital, where Professor A. Wormall, F.R.S., has provided excellent research facilities, and my thanks are also due to Dr E. D. Wills and other members of the Biochemistry Department for helpful suggestions. Miss A. Routledge gave valuable technical assistance.

\section{REFERENCES}

Axelrod, L. R. (1953). J. biol. Chem. 201, 59.

Beer, C. T. \& Gallagher, T. F. (1955). J. biol. Chem. 214, 335.

Burton, R. B., Zaffaroni, A. \& Keutmann, E. H. (1951). J. biol. Chem. 188, 763.

Calvin, M. (1949). In Isotopic Carbon. Ed. by Calvin, M., Heidelberger, C., Reid, J. C., Tolbert, B. M. \& Yankwich, P. E. New York: John Wiley and Sons.

Cohen, P. P. (1949). In Manometric Techniques and Tissue Metabolism, 2nd ed. Ed. by Umbreit, W. W., Burris, R. H. \& Stauffer, J. F. Minneapolis: Burgess Publishing Co.

De Meio, R. H., Rakoff, A. E., Cantarow, A. \& Paschkis, K. E. (1948). Endocrinology, 43, 97.

Engel, P. \& Rosenberg, E. (1945). Endocrinology, 37, 44.

Fieser, L. F. \& Fieser, M. (1949). Natural Products related to Phenanthrene. New York: Reinhold Publishing Co.

Francis, G. E., Mulligan, W. \& Wormall, A. (1954). Isotopic Tracers. London: The Athlone Press.

Garst, J. B. \& Friedgood, H. B. (1952). Science, 116, 65.

Graubard, M. \& Pincus, G. (1941). Proc. nat. Acad. Sci., Wash., 27, 149.

Heard, R. D. H., Jacobs, R., O'Donnell, V. J., Peron, F. G., Saffran, J. C., Solomon, S. S., Thompson, L. M., Willoughby, H. \& Yates, C. H. (1954). Recent Progr. Hormone Res. 9, 383.

Heller, C. (1940). Endocrinology, 26, 619.

Jellinck, P. H. (1953). Nature, Lond., 171, 750.

Kraychy, S. \& Gallagher, T. F. (1957). J. Amer. chem. Soc. 79, 754.

Krebs, H. A. \& Eggleston, L. V. (1940). Biochem. J. 34, 442.

Levy, H. (1947). Arch. Biochem. 14, 325.

Pearlman, W. H. \& De Meio, R. H. (1949). J. biol. Chem. 179, 1141.

Ryan, K. J. \& Engel, L. L. (1953). Endocrinology, 52, 277.

Thompson, L. M. (1951). Ph.D. Thesis: McGill University, Montreal.

Valcourt, A. J., Thayer, S. A., Doisy, E. A. jun., Elliott, W. H. \& Doisy, E. A. (1955). Endocrinology, 57, 692.

Westerfeld, W. W. (1940). Biochem. J. 34, 51.

Wills, E. D. \& Wormall, A. (1950). Biochem. J. 47, 158.

Wotiz, H. H., Ziskind, B. S. \& Ringler, I. (1958). J. biol. Chem. 231, 593.

Zondek, B. (1934). Skand. Arch. Physiol. 70, 133. 